\title{
Mass spectrometric analysis of the interactions between CP12, a chloroplast protein, and metal ions: a possible regulatory role within a PRK/GAPDH/CP12 complex
}

\author{
Arnaud Delobel ${ }^{1 \dagger}$, Emmanuelle Graciet ${ }^{2 \$}$, Simona Andreescu ${ }^{2}$, Brigitte Gontero ${ }^{2}$, \\ Frédéric Halgand $^{1 *}$ and Olivier Laprévote ${ }^{1}$ \\ ${ }^{1}$ Institut de Chimie des Substances Naturelles, CNRS, 1 avenue de la terrasse, 91198 Gif/Yvette, France \\ ${ }^{2}$ Laboratoire Génétique et Membranes, Département Biologie Cellulaire, Institut Jacques Monod, UMR 7592 CNRS, \\ Universités Paris VI-VII, 2 place Jussieu, 75251 Paris cedex 05, France
}

Received 25 June 2005; Revised 7 September 2005; Accepted 8 September 2005

\begin{abstract}
The small chloroplast protein CP12 plays the role of a protein linker in the assembly process of a PRK/GAPDH/CP12 complex that is involved in $\mathrm{CO}_{2}$ assimilation in photosynthetic organisms. The redox state of CP12 regulates its role as a protein linker. Only the oxidized protein, with two disulfide bonds, is active in complex formation. Several observations indicating that CP12 might bind a metal ion led us to screen the binding of different metal ions on oxidized or reduced CP12 using non-covalent electrospray ionization mass spectrometry (ESI-MS) experiments. The oxidized protein bound specifically $\mathrm{Cu}^{2+}$ and $\mathrm{Ni}^{2+}\left(\mathrm{K}_{\mathrm{d}}\right.$ of $26 \pm 1 \mu \mathrm{M}$ and $11 \pm 1 \mu \mathrm{M}$, respectively); other cations such as $\mathrm{Fe}^{2+}$ and $\mathrm{Zn}^{2+}$ did not bind, while cations such as $\mathrm{Cd}^{2+}$ formed non-specific adducts to CP12. Similar results were obtained for metal ions on screening with the reduced CP12. Interestingly, the present results suggest that $\mathrm{Cu}^{2+}$ catalyzes the re-formation of the disulfide bonds of the reduced $\mathrm{CP12}$, leading to recovery of the fully oxidized CP12 that is then able to bind a $\mathrm{Cu}^{2+}$ ion. Finally the high similarity between CP12 and copper chaperones from Arabidopsis thaliana, as judged by hydrophobic cluster analysis, provides additional evidence for the relevance of metal binding for the in vivo situation. The findings that $\mathrm{CP} 12$ is able to bind a metal ion, and that $\mathrm{Cu}^{2+}$ catalyzes the oxidation of the thiol groups of $\mathrm{CP12}$, are new characteristics of this protein that may prove to be important in the regulation of the assembly process of the PRK/GAPDH/CP12 complex. Copyright $(\mathbb{C} 2005$ John Wiley \& Sons, Ltd.
\end{abstract}

Many proteins are functional in a combinatorial manner and establish a dynamical network of interactions with other specific proteins. Determination of these interaction patterns is an essential part of functional genomic research. Recently, proteomic approaches, coupled to other methods, ${ }^{1,2}$ have been developed to obtain information about the different sets of protein-protein interactions that might exist in the cell depending on its physiological state, the environmental conditions, or genetic background. ${ }^{3}$ The analysis of these interactions is probably one of the most important challenges for the years to come. ${ }^{3}$

Among all techniques used to study biological macromolecular complexes, electrospray ionization mass spectrometry (ESI-MS) is well suited to characterize the subunits and ligand binding stoichiometry, as well as the regulatory

*Correspondence to: F. Halgand, ICSN-CNRS, 1 Av de la terrasse, 91198 Gif-sur-Yvette, France.

E-mail: halgand@icsn.cnrs-gif.fr

Tresent address: Mass Spectrometry Laboratory; Department of Chemistry, University of Liège, 4000 Liège (Sart-Tilman), Belgium.

Present address: California Institute of Technology, Division of Biology, 147-75, 1200 East California Blvd., Pasadena, CA 91125, USA. properties of non-covalently bound species; the subject has been well reviewed by Heck and Van Den Heuvel. ${ }^{4}$ Advantages of this method lie in its speed, sensitivity and accuracy. The technique possesses several advantages versus other spectroscopic methods: (i) it requires moderate amounts of protein; (ii) all metal ions are theoretically observable regardless of their electronic properties; and (iii) it is well suited for competition experiments.

Determination of equilibrium constants by ESI-MS has usually involved titration experiments; a frequent assumption made for this approach is that the ionization efficiencies for both complexed and non-complexed species are the same. Thus, it is still debatable whether or not the relative ion abundances reflect the relative concentrations of species in solution. However, it is not possible to determine the signalresponse factor of a non-covalent complex in solution unless its dissociation constant is already known. To overcome these problems, different groups have introduced an internal standard that allows relative quantitation of complexed and free species, ${ }^{5}$ or a so-called $\mathrm{R}$-factor that gives a relative measurement of the signal response for free and complexed species. ${ }^{6}$ However, most of the examples in which ESI was used for determination of binding constants did not consider 
these aspects. Nonetheless, the results obtained were in reasonable agreement with the values determined by solution-phase methods.

Numerous applications of ESI-MS to the study of noncovalently bound complexes have been reported; such studies determine complex stoichoimetry or describe biological properties of protein-ligand, protein-protein, proteinmetal ions, DNA-ligand complexes, etc. In addition, this approach also allows the determination of dissociation constants of weakly bound non-covalent complexes, with $\mathrm{K}_{\mathrm{d}}$ values ranging from milli- to micro-molar. ${ }^{7-10}$

A protein complex involved in the Benson-Calvin cycle, responsible for $\mathrm{CO}_{2}$ assimilation in photosynthetic organisms, has been isolated from plants. ${ }^{11,12}$ It is composed of phosphoribulokinase (PRK)/glyceraldehyde-3-phosphate dehydrogenase (GAPDH)/CP12, and has also been found in green algae such as Chlamydomonas reinhardtii ${ }^{13,14}$ and Scenedesmus obliquus, ${ }^{15,16}$ and in the cyanobacterium Synechocystis PCC6803. ${ }^{14}$ The small nuclear-encoded $8.5-\mathrm{kDa}$ protein, named $\mathrm{CP} 12$, has been recently identified in most of these complexes whether they originated from higher plants, green algae or cyanobacteria. ${ }^{14,17}$ This protein consists of about 80 residues with four conserved cysteine residues. It also shares sequence similarities with part of the C-terminal extension of the GAPDH B subunit that contains the regulatory cysteine residues, ${ }^{16}$ suggesting similarity to GAPDH, a redox regulator of the CP12 protein activity. ${ }^{18}$

Secondary structure predictions suggest that CP12 might possess two peptide loops formed via two disulfide bonds between the two N-terminal cysteine residues and the two C-terminal ones. ${ }^{17}$ It was also proposed that these putative loops play a role in the formation of the complex, and particularly that the interaction between GAPDH and CP12 occurs at the C-terminal peptide loop of CP12, while the interaction of CP12 with PRK occurs at the N-terminal peptide loop of CP12. ${ }^{14}$ Recently, the role of $\mathrm{CP} 12$ in the assembly process of a PRK/GAPDH/CP12 complex from C. reinhardtii was characterized by surface plasmon resonance and in vitro reconstitution experiments. ${ }^{19}$ It was shown that the first step in the assembly process of the complex is the association of $\mathrm{CP} 12$ with GAPDH that results in a change of conformation and kinetic properties of GAPDH. This GAPDH/CP12 sub-complex then becomes associated with PRK. ${ }^{19}$ These findings indicated that $\mathrm{CP} 12$ may act as a linker in the assembly of the PRK/GAPDH/CP12 complex. Only the oxidized $\mathrm{CP} 12$, with its two disulfide bonds, was able to act as a linker, signifying that the role of CP12 in complex assembly is dependent on its redox state. A change in redox state of CP12 is also accompanied by a structural change; circular dichroism and nuclear magnetic resonance spectra showed that oxidized CP12 is mainly composed of $\alpha$-helices plus random coil, while upon reduction it becomes disorganized and very flexible. CP12 has physicochemical properties similar to those of intrinsically unstructured proteins (IUP) which are involved in protein-protein interactions, and play major roles in cellular functions. ${ }^{20-25}$

Another intriguing observation regarding $\mathrm{CP} 12$ is that the recombinant protein purified by affinity chromatography on a nickel column has a yellow color, even after extensive dialysis with buffer depleted in metal and imidazole. The absorption spectra from 280 to $600 \mathrm{~nm}$ were similar to those of ferredoxin, with a broad peak around $410 \mathrm{~nm}$. Functional domain prediction using a NCBI conserved domain search suggested that a zinc-binding domain might exist in CP12. All these observations led to the hypothesis that CP12 could bind a metal ion. Therefore, non-denaturing MS experiments were designed in order to (i) identify which metal ions CP12 would be able to bind, and (ii) to measure the dissociation constants of complexes between CP12 and those metal ions that could specifically bind to $\mathrm{CP} 12$, and hence characterize the specificity of this binding.

\section{EXPERIMENTAL}

\section{Materials}

Most metal ions, as $\mathrm{CaCl}_{2}, \mathrm{CdSO}_{4}, \mathrm{CoCl}_{2}, \mathrm{MnCl}_{2}, \mathrm{MgCl}_{2}$, $\mathrm{ZnSO}_{4}, \mathrm{NiSO}_{4}, \mathrm{Fe}\left(\mathrm{NO}_{3}\right)_{3}, \mathrm{FeSO}_{4},\left(\mathrm{NH}_{4}\right)_{2} \mathrm{Fe}\left(\mathrm{SO}_{4}\right)_{2}$ and $\mathrm{CuCl}_{2}$, were supplied by Merck. EDTA and dithiothreitol (DTT) were from Sigma. EndoLysC was obtained from Pierce Chemicals (Rockford, IL, USA).

\section{CP12 purification}

Recombinant wild-type Chlamydomonas gene and mutant H47L CP12 were purified to apparent homogeneity, as previously described. ${ }^{19}$ Standard and reverse primers used for mutant H47L recombinant CP12 were 5'-CTC AGC GCT GCT GTC TCG CTT AAG AAG GAT GCC GTC-3' and 5'GAC GGC ATC CTT CTT AAG CGA GAC AGC AGC GCT GAG-3', respectively. The histidine tag was removed using Factor Xa, according to the manufacturer's instructions (Novagen). Site-directed mutagenesis was performed using a QuickChange ${ }^{\mathrm{TM}}$ site-directed mutagenesis kit (Stratagene). Introduction of the point mutation H47L and absence of additional mutations were confirmed by DNA sequencing.

\section{Mass spectrometric sample preparation}

Prior to MS experiments, CP12 was desalted using an ultrafree membrane filter with a cut-off of $3000 \mathrm{Da}$ (Millipore). $\mathrm{CP} 12$ concentration was then determined with the Bradford assay using bovine serum albumin (BSA) as standard. ${ }^{26}$ For MS analyses in denaturing conditions, the CP12 was diluted in a water $/ \mathrm{MeOH} /$ acetic acid solution (50:50:1, v/v/v). For measurements under non-denaturing conditions, the protein was diluted in $20 \mathrm{mM}$ ammonium acetate ( $\mathrm{pH}$ 6.8) at a protein final concentration of 5 or $2 \mu \mathrm{M}$. Cation-binding studies were performed by adding increasing metal-ion concentrations to a fixed protein concentration of $5 \mu \mathrm{M} .{ }^{27}$ Reduced CP12 was obtained after incubation of the oxidized form of the protein with $1 \mathrm{mM} \mathrm{DTT} \mathrm{(pH} \mathrm{7.8)} \mathrm{at} 37^{\circ} \mathrm{C}$ for $1 \mathrm{~h}$. When necessary the cysteine residues were alkylated with $5 \mathrm{mM}$ iodoacetamide (IAA) solution. Then the reduced, or the reduced and alkylated, protein was desalted as described above and was directly analyzed by MS under denaturing or non-denaturing conditions, as well as under strongly acidic conditions $\left(\mathrm{HCOOH} / \mathrm{H}_{2} \mathrm{O}, 70: 30, \mathrm{v} / \mathrm{v}\right)$.

\section{Electrospray mass spectrometry (ESI-MS)}

Metal ion/protein complexes were analyzed using a hybrid Qq-TOF mass spectrometer (Q-Star Pulsar, Applied Biosystems, Les Ulis, France) fitted with an ionspray source. Instrumental parameters (values of ion spray voltage (ISV), 
nebuliser and curtain gas (GS1 and GS2), declustering potential (DP1 and DP2) and focusing potential (FP)) were optimized in order to obtain the best sensitivity without disrupting non-covalent interactions. The parameters used were the following: GS1 $=55$ psi, GS2 $=45$ psi, DP $1=150 \mathrm{~V}$, $\mathrm{FP}=125 \mathrm{~V}, \mathrm{DP} 2=15 \mathrm{~V}$. The mass spectrometer was calibrated with a $3 \mathrm{mM}$ cesium iodide solution in 50:50 isopropanol/ water $(\mathrm{v} / \mathrm{v})$ for an $\mathrm{m} / \mathrm{z}$ range 580-3000. Samples were introduced into the mass spectrometer at a flow rate of $5 \mu \mathrm{L} / \mathrm{min}$.

During MS experiments designed to characterize noncovalent complexes, the acquisition time was shortened to $30 \mathrm{~s}$ to get rid of memory effects due to metal-ion retention in the PEEK tube during the course of a MS run from one experiment to another, while still attaining a good signalto-noise ratio. To avoid the non-specific accumulation of these metal ions, the tubing was washed with $200 \mu \mathrm{M}$ EDTA in a $200 \mathrm{mM}$ ammonium acetate solution prior to any measurements.

\section{MALDI-MS}

To assess whether the two disulfide bonds of oxidized CP12 occurred between the pairs of cysteine residues C23 and C31, and $\mathrm{C} 66$ and $\mathrm{C} 75$ (C. reinhardtii numbering), the protein was digested with EndoLysC at $37^{\circ} \mathrm{C}$ for $15 \mathrm{~h}$ in $20 \mathrm{mM}$ ammonium bicarbonate ( $\mathrm{pH} 7.8$ ), with a protease-to-substrate ratio of 1:100 (w/w). The digest mixture was then divided into two parts. The first aliquot was acidified with acetic acid in order to prevent disulfide bond recombination, and the second was treated with $1 \mathrm{mM}$ DTT (pH 7.8). Peptide mapping of both these digest fractions was recorded using a matrix-assisted laser desorption/ionization time-of-flight (MALDI-TOF) Voyager DE STR mass spectrometer (Applied Biosystems, Les Ulis, France). MALDI mass spectra were acquired in the reflectron mode, with an $m / z$ range 500-3000, a grid percentage of $60 \%$, a delayed extraction time of $300 \mathrm{~ns}$, and a laser intensity setting of 1869. Calibration was performed with a standard peptide mixture solution (Pepmix 4, LaserBioLabs, Sophia-Antipolis, France).

\section{Determination of the dissociation constants}

Data were fitted to theoretical curves defined by Eqns. (1), (2) and (3), given below, using ORIGIN Pro 7 software (Copyright, 1991-2003, OriginLab Corp., Northampton, MA, $\mathrm{USA}^{28}$ ).

\section{Alkylation experiments}

The free $\mathrm{SH}$ groups in CP12 were quantified and mapped by alkylation with IAA as previously described. ${ }^{29}$ After desalting, samples were analyzed by MALDI-TOFMS.

\section{Hydrophobic cluster analyses}

We used the bidimensional hydrophobic cluster analysis (HCA), 30,31 which offers the possibility to add information about secondary structures to the lexical analysis of the considered sequences. The sequence is handled on a duplicated $\alpha$-helical net in which hydrophobic amino acids (V, I, L, F, M, Y, W) are contoured. The defined hydrophobic clusters (i.e. hydrophobic amino acids that are separated from each other by at least four non-hydrophobic residues, a connectivity distance linked to the use of an $\alpha$-helical support) were shown to mainly correspond to the internal faces of reg- ular secondary structures ( $\alpha$-helices or $\beta$-strands). ${ }^{32}$ Conservation of hydrophobic cluster features which participate in the protein core, together with a similar texture of sequence similarities, are associated with the maintenance of a similar structure and often help and/or allow the alignment procedure for highly divergent sequences (typically in the 10-20\% sequence identity range, below the so-called twilight zone of 25-30\% identity).

\section{RESULTS}

\section{Metal-ion screening on oxidized CP12}

Mass spectrometric analysis in denaturing conditions gave a molecular mass in good agreement with the theoretical molecular mass of oxidized CP12 $(8734.3 \pm 0.2 \mathrm{Da}$, data not shown). Under non-denaturing conditions, the oxidized CP12 (CP12ox) was characterized by a charge-state distribution (CSD) of ions spanning from +4 to +8 charges (Fig. 1(A)), with major charge states +5 and +6 . To avoid any discrimination effects all charge states were considered for metal-ion screening, as well as for calculation of the dissociation constants. According to the measured masses, under both denaturing and non-denaturing conditions, the CP12ox possesses two disulfide bridges that are formed between cysteine residues $\mathrm{C} 23$ and $\mathrm{C} 31$, and C66 and C75, as confirmed by the peptide mapping of the EndoLysC-digested CP12ox (data not shown).

We first screened the complexation properties of different metal ions by recording the ESI mass spectra of $5 \mu \mathrm{M} \mathrm{CP} 12$ in the presence of a 20-fold molar excess of metal ions. Different behaviors were observed, depending on the nature of the metal ion bound to CP12. For example, in the presence of $\mathrm{Fe}^{2+}$ and $\mathrm{Fe}^{3+}$, no protein/metal complex was observed (Fig. 1(B)). For other metal ions such as $\mathrm{Cd}^{2+}$, several species were observed, the major one corresponding to the free CP12ox and others to CP12ox complexed with one to three $\mathrm{Cd}^{2+}$ ions (Fig. 1(D)). This result was obtained for a protein/metal-ion ratio 1:20 or lower. The presence of a high amount of cadmium-ion adducts with the CP12ox suggests a nonspecific binding of this cation to the protein. In contrast, for $\mathrm{Cu}^{2+}$ (Fig. 1(C)) and $\mathrm{Ni}^{2+}$ (not shown), the major species observed in the mass spectra was the $\mathrm{CP} 12$ ox complexed with a single $\mathrm{Cu}^{2+}$ or $\mathrm{Ni}^{2+}$ cation.

To discriminate between non-specific and specific binding, we considered the distribution of species; if the distribution displayed a statistical distribution of a large number of ion adducts on the protein, the binding was considered nonspecific. In contrast, if only one protein/metal species was observed, independently of the protein/metal-ion ratio and with a well-defined stoichiometry, this interaction was considered as specific. According to this criterion, only the binding of $\mathrm{Cu}^{2+}$ and $\mathrm{Ni}^{2+}$ to CP12ox could be considered as specific, which led us to determine the dissociation constants of the CP12ox $/ \mathrm{Cu}^{2+}$ and $\mathrm{CP} 12$ ox $/ \mathrm{Ni}^{2+}$ complexes.

\section{Calculation of dissociation constants of CP12ox $/ \mathrm{Cu}^{2+}$ and CP12ox/ $/ \mathrm{Ni}^{2+}$ complexes}

As the CSDs of the free and complexed forms of CP12ox were identical, it was concluded that it could be approximated that the binding of the ligand did not promote any drastic 

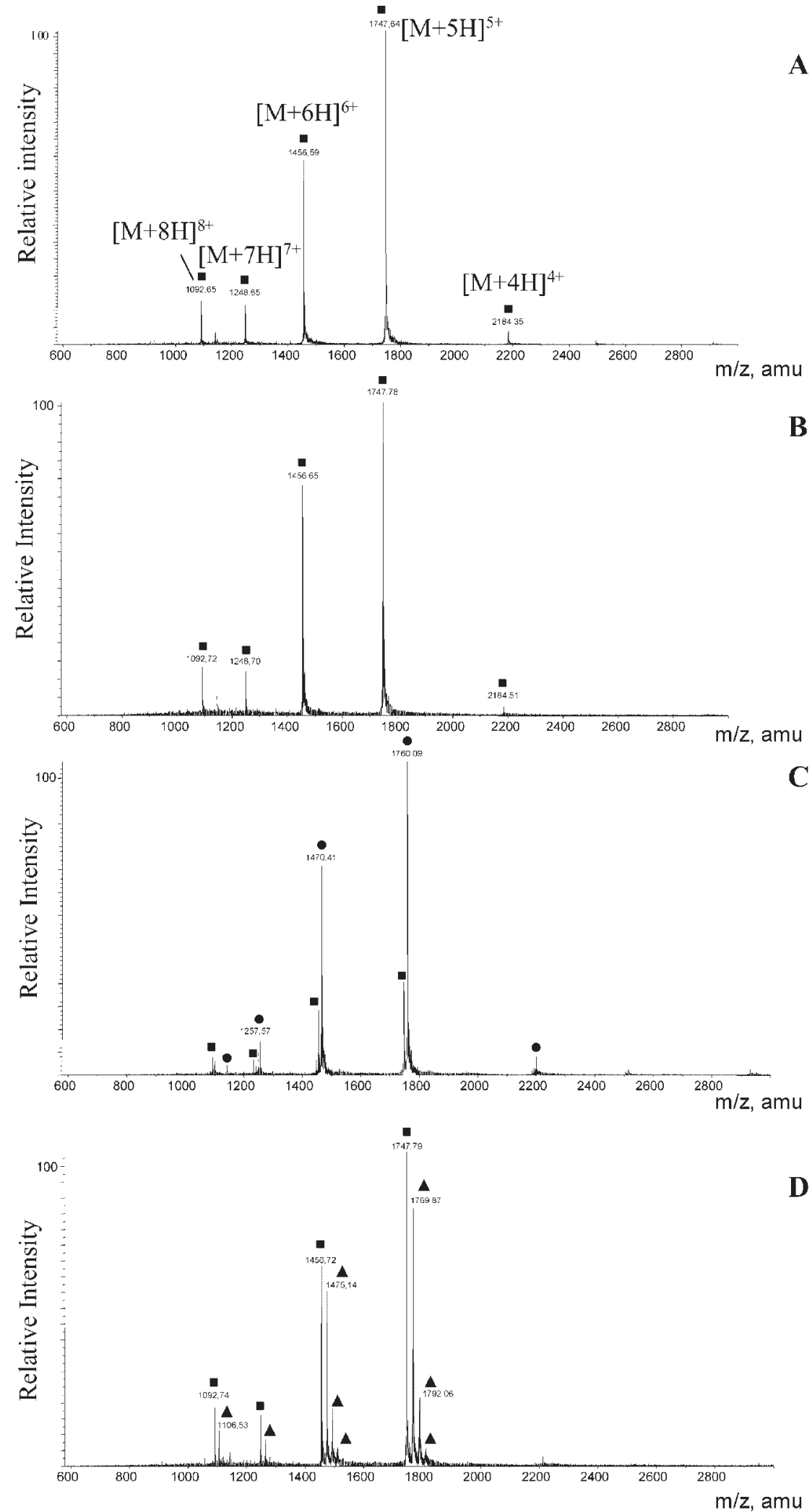

Figure 1. ESI mass spectra of the oxidized CP12 protein without or with metal ions. (A) ESI mass spectrum of the free oxidized $C P 12$ protein. $(B, C, D) E S I$ mass spectra of the oxidized $\mathrm{CP} 12$ protein in the presence of $\mathrm{Fe}^{2+}(\mathrm{B}), \mathrm{Cu}^{2+}(\mathrm{C})$ and $\mathrm{Cd}^{2+}(\mathrm{D})$, at a molar ratio protein/metal ion of $1: 20$ with a fixed protein concentration of $5 \mu \mathrm{M}$. Labels: $\square$ : free CP12ox, $\mathrm{O}$ : $\mathrm{CP} 12 / \mathrm{Cu}^{2+}$ complex, $\mathrm{CP} 12 / \mathrm{Cd}^{2+}$ complexes. 

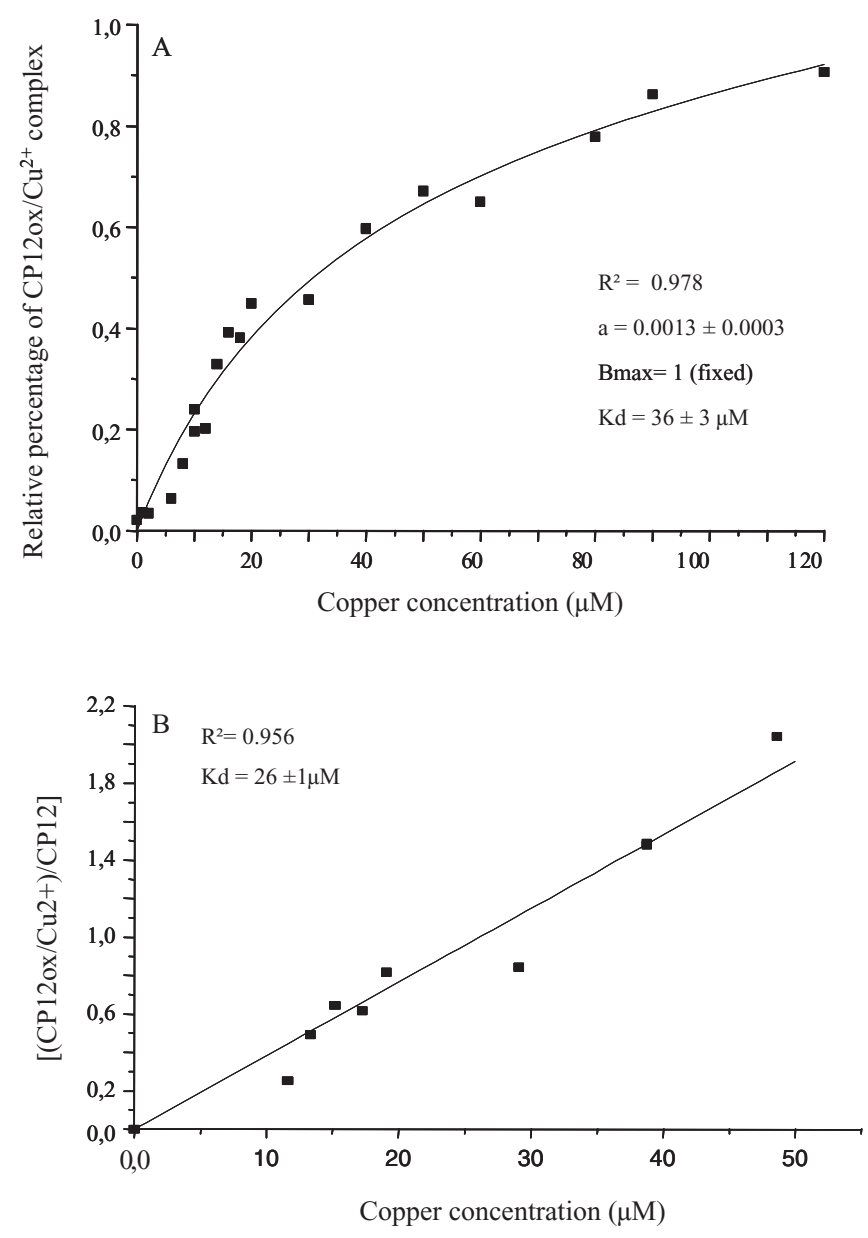

Figure 2. Titration of the CP12ox by $\mathrm{Cu}^{2+}$. Saturation $(\mathrm{A})$ and linear correlation (B) curves for the formation of the $\mathrm{CP} 120 \mathrm{x} / \mathrm{Cu}^{2+}$ complex as a function of increasing concentrations of metal ion (from 0 to $120 \mu \mathrm{M}$ ), with a fixed protein concentration of $2 \mu \mathrm{M}$. Linear regression calculations (Eqn. (3)) allowed determination of a dissociation constant of $26 \pm 1 \mu \mathrm{M}$ for the CP12ox/Cu${ }^{2+}$ complex.

conformational changes of CP12ox and that, most importantly, both forms had similar desorption and ionization yields. Thus, the two CP12ox species (CP12ox alone and complexed to a metal) differed only by a mass increase due to the binding of the metal ions. On this basis the relative ion abundances recorded for the free and complexed CP12ox can be directly linked to their relative concentrations in solution. To determine the dissociation constants, we recorded the mass spectra of $\mathrm{CP} 12 \mathrm{ox}$ with increasing concentrations of metal ions $\left(\mathrm{Cu}^{2+}\right.$ or $\left.\mathrm{Ni}^{2+}\right)$, ranging from 0 to $120 \mu \mathrm{M}$, at a fixed protein concentration of $2 \mu \mathrm{M}$. Dissociation constants were then deduced from the relative concentrations of bound and free CP12ox. The experimental data were first fitted to a hyperbola:

$$
[\mathrm{PM}] /[\mathrm{P}]_{\mathrm{tot}}=[\mathrm{M}] /\left(\mathrm{K}_{\mathrm{d}}+[\mathrm{M}]\right)
$$

where $[\mathrm{P}]_{\text {tot }}$ is the total protein concentration, $[\mathrm{M}]$ the free metal-ion concentration, [PM] the CP12/metal-ion complex concentration, and $\mathrm{K}_{\mathrm{d}}$ the dissociation constant.

The experimental data followed a sigmoidal curve (Figs. 2(A) and 3(A)) and did not fit the theoretical curve deduced from Eqn. (1). The sigmoid may be explained by an underestimation of the relative intensity of CP12ox bound to the metal ion at low $\mathrm{CP} 12 /$ metal-ion ratios because of a competition between the specific binding of the metal ion to CP12ox and adsorption onto the PEEK tube. In addition, at high metal-ion/CP12 ratios the concentration of complexed CP12ox is over-estimated, even with a short acquisition time, because of the formation of additional CP12ox/metal-ion complexes with residual cations released by the PEEK tube prior to the transfer of the molecules in the gas phase. To take this non-specific binding into account, the data were fitted to the following equation:

$$
[\mathrm{PM}] /[\mathrm{P}]_{\mathrm{tot}}=[\mathrm{M}] /\left(\mathrm{K}_{\mathrm{d}}+[\mathrm{M}]\right)+\mathrm{a}[\mathrm{M}]
$$

where the term $\mathrm{a}[\mathrm{M}]$ corresponds to the proportion of the metal ion responsible for the over-estimation of the CP12/ metal-ion complex.

The resulting correlation coefficients were 0.978 and 0.927 for $\mathrm{Cu}^{2+}$ and $\mathrm{Ni}^{2+}$, respectively. The worst fitted parts corresponded to the beginning and the end of the curves. To avoid these problems, only the central parts of the curves were fitted to Eqn. (3). In this case, the proportion of the complexed species is linearly related to the ligand concentration:

$$
[\mathrm{PM}] /[\mathrm{P}]=1 /\left(\mathrm{K}_{\mathrm{d}}\right)[\mathrm{M}]
$$

Using a linear regression with Eqn. (3), the dissociation constants of CP12ox $/ \mathrm{Cu}^{2+}$ and CP12ox $/ \mathrm{Ni}^{2+}$ were determined (Figs. 2(B) and 3(B)). $\mathrm{K}_{\mathrm{d}}$ values were $26 \pm 1 \mu \mathrm{M}$ for the $\mathrm{CP} 12 \mathrm{ox} / \mathrm{Cu}^{2+}$ complex and $11 \pm 1 \mu \mathrm{M}$ for the $\mathrm{CP} 12 \mathrm{ox} / \mathrm{Ni}^{2+}$ complex.

\section{Effect of the His 47 Leu mutation on metal-ion binding}

Amino acids that are involved in the binding of cations in proteins are well characterized. Among them, histidine plays an important role. ${ }^{33}$ The comparison of amino acid sequences of various $\mathrm{CP} 12 \mathrm{~s}$ from different organisms revealed the presence of a highly conserved histidine residue in position $47,{ }^{19}$ which could potentially play a role in the binding of a metal ion. Screening of the binding properties of the different metal ions for the H47L CP12 mutant showed that the mutation did not affect the behavior of $\mathrm{CP} 12$ towards the metal ions tested (data not shown). In addition, the dissociation constant calculated in the presence of $\mathrm{Cu}^{2+}$ was similar to that obtained with the wild-type CP12ox $(27 \pm 1 \mu \mathrm{M}$, data not shown). Hence, His 47 is not essential for metal-ion binding.

\section{Metal screening on reduced CP12: catalysis of disulfide bond formation by $\mathrm{Cu}^{2+}$}

Since it has been shown previously that, upon reduction of its two disulfide bridges, $\mathrm{CP} 12$ becomes more flexible and unstructured, a study of the reduced CP12 (CP12red) was conducted to determine whether the greater flexibility and the availability of four free $\mathrm{SH}$ groups would change the metal-ion-binding properties of CP12 (Fig. 4).

Surprisingly, MS control analysis on CP12red under both non-denaturing and denaturing conditions gave a molecular mass of $8737.9 \pm 0.2 \mathrm{Da}$, which is $1 \mathrm{Da}$ less than expected (Fig. 4(A)). This extremely reproducible result was obtained with several independent sample preparations. Moreover, 

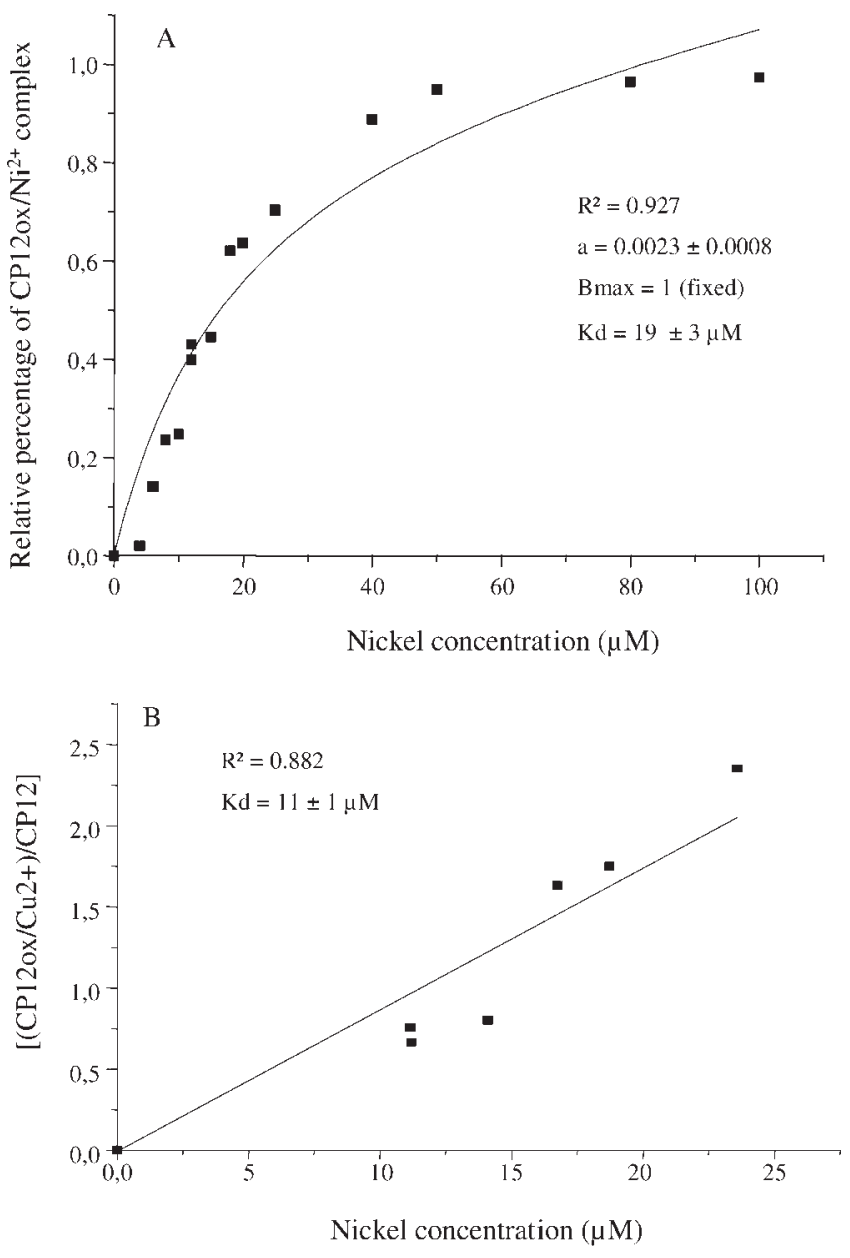

Figure 3. Titration of the CP120x by $\mathrm{Ni}^{2+}$. Saturation $(A)$ and linear correlation (B) curves for the CP120x/ $/ \mathrm{Ni}^{2+}$ complex as a function of increasing concentrations of $\mathrm{Ni}^{2+}$ (from 0 to $110 \mu \mathrm{M}$ ), with a fixed protein concentration of $2 \mu \mathrm{M}$. Linear regression calculations (Eqn. (3)) allowed determination of the dissociation constant of $11 \pm 1 \mu \mathrm{M}$ for the CP12ox/ $\mathrm{Ni}^{2+}$ complex.

the CP12red was not stable during the course of the experiments ( 1 day). Its average mass varied from $8737.9 \pm 0.2 \mathrm{Da}$ at the beginning of the experiment to $8734.4 \pm 0.2 \mathrm{Da}$, corresponding to the fully oxidized $\mathrm{CP} 12$, strongly suggesting that the disulfide bonds spontaneously formed in solution during the course of the experiment. The next measurements were performed on freshly reduced $\mathrm{CP} 12$ protein.

In order to determine whether or not the presence of a thiolate among the four cysteine residues could be responsible for the mass difference of $1 \mathrm{Da}$, the CP12red was alkylated with IAA and digested by EndoLysC. The MALDI mass spectrum obtained for the resulting peptide mixture showed that the protein bore four alkylated cysteine residues (data not shown), indicating that the $1 \mathrm{Da}$ mass difference was not linked to the presence of a mixed population of reduced and oxidized CP12 in the sample. In contrast, the homogeneity of the $\mathrm{CP} 12$ population in its reduced form is in agreement with the presence of three $\mathrm{SH}$ groups and a more reactive thiolate. To confirm this hypothesis, the mass spectrum of $\mathrm{CP} 12$ red was recorded under very acidic conditions (70\% formic acid, data not shown). In this case no mass difference was observed, with a measured mass of $8738.8 \pm 0.2 \mathrm{Da}$, indicating the presence of four $\mathrm{SH}$ groups. This set of data demonstrated that the $\mathrm{CP} 12$ red contains three $\mathrm{SH}$ groups and a thiolate $\left(\mathrm{S}^{-}\right)$group under non-acidic conditions.

Under non-denaturing conditions, the ESI mass spectrum of reduced CP12 was characterized by a CSD of ions spanning from +4 to +8 charges (Fig. $4(\mathrm{~A})$ ); the major charge states of $\mathrm{CP} 12$ red are +5 and +6 . For most of the metal ions studied, screening of the binding of metal ions on CP12red gave the same results as those described for CP12ox, in terms of specificity and CP12/cation peak intensities. The non-specific adduct formation with $\mathrm{Cd}^{2+}$ (Fig.4(A)) was, however, more pronounced, as the peak corresponding to free CP12red was of very low intensity. Intense peaks corresponding to up to eight $\mathrm{Cd}^{2+}$ adducts were observed (Fig. 4(D)). In contrast to the CP12ox, the major peaks of the CP12red $/ \mathrm{Cd}^{2+}$ complex corresponded to CP12red with four and five $\mathrm{Cd}^{2+}$ adducts. This result can be attributed to a larger accessibility of the reduced CP12 to the metal ions, due to its unstructured and flexible properties after reduction by DTT. ${ }^{19}$

The greatest difference was observed in the presence of $\mathrm{Cu}^{2+}$ (Fig. 4(B)). At a molar protein/metal-ion ratio of 1:20, the major species observed with $\mathrm{CP} 12$ ox was the protein complexed with one $\mathrm{Cu}^{2+}$, whereas, with the reduced CP12, the major species was the free protein (60\% intensity) with the complexed form representing $40 \%$ of the total CP12 protein intensity. It was very striking that the measured mass of the free CP12 corresponded to that of the CP12ox (8734.6 $0.2 \mathrm{Da}$ ), and that the measured mass of the CP12red/Cu ${ }^{2+}$ complex was identical to that of the mass of the $\mathrm{CP} 12 \mathrm{ox} / \mathrm{Cu}^{2+}$ complex. This result strongly suggests that $\mathrm{Cu}^{2+}$ regenerates the oxidized form of $\mathrm{CP} 12$, which would then be able to bind one $\mathrm{Cu}^{2+}$ cation.

To test this hypothesis we attempted to observe reoxidation intermediates, by recording re-oxidation kinetics of the CP12red in the presence of smaller CP12red/copper ratios (1:1 and 1:2; data not shown). Mass spectra were acquired for $10 \mathrm{~min}$ and masses of the free $\mathrm{CP} 12$ were determined every $30 \mathrm{~s}$. This experiment confirms that the first species observed corresponds to the CP12red and that the $\mathrm{m} / \mathrm{z}$ values of the CP12 charge states shifted towards those of the oxidized form of $\mathrm{CP} 12$ in the presence of copper. Given the redox properties of copper, we hypothesized that the oxidation of the thiol groups of cysteine residues could occur through the formation of an intermediate complex that would include one or two atoms of $\mathrm{Cu}^{2+}$ cross-linked by cysteine residues. The presence of a majority of free CP12 (60\%), although $\mathrm{Cu}^{2+}$ was added in huge excess, was intriguing (Fig. 4(B)). Even if part of the copper was used to regenerate disulfide bonds, which led it to be present in a redox state not suitable for complexation with $\mathrm{CP} 12$, one would still expect the CP12ox / $\mathrm{Cu}^{2+}$ complex to be the main species in the mass spectrum. In the absence of any structural information on the free CP12 in its different redox states and intermediates, it would be hazardous to make any assumptions as to the putative structural changes that may occur upon re-oxidation of $\mathrm{CP} 12$ by copper. Nonetheless, it cannot be excluded that the 

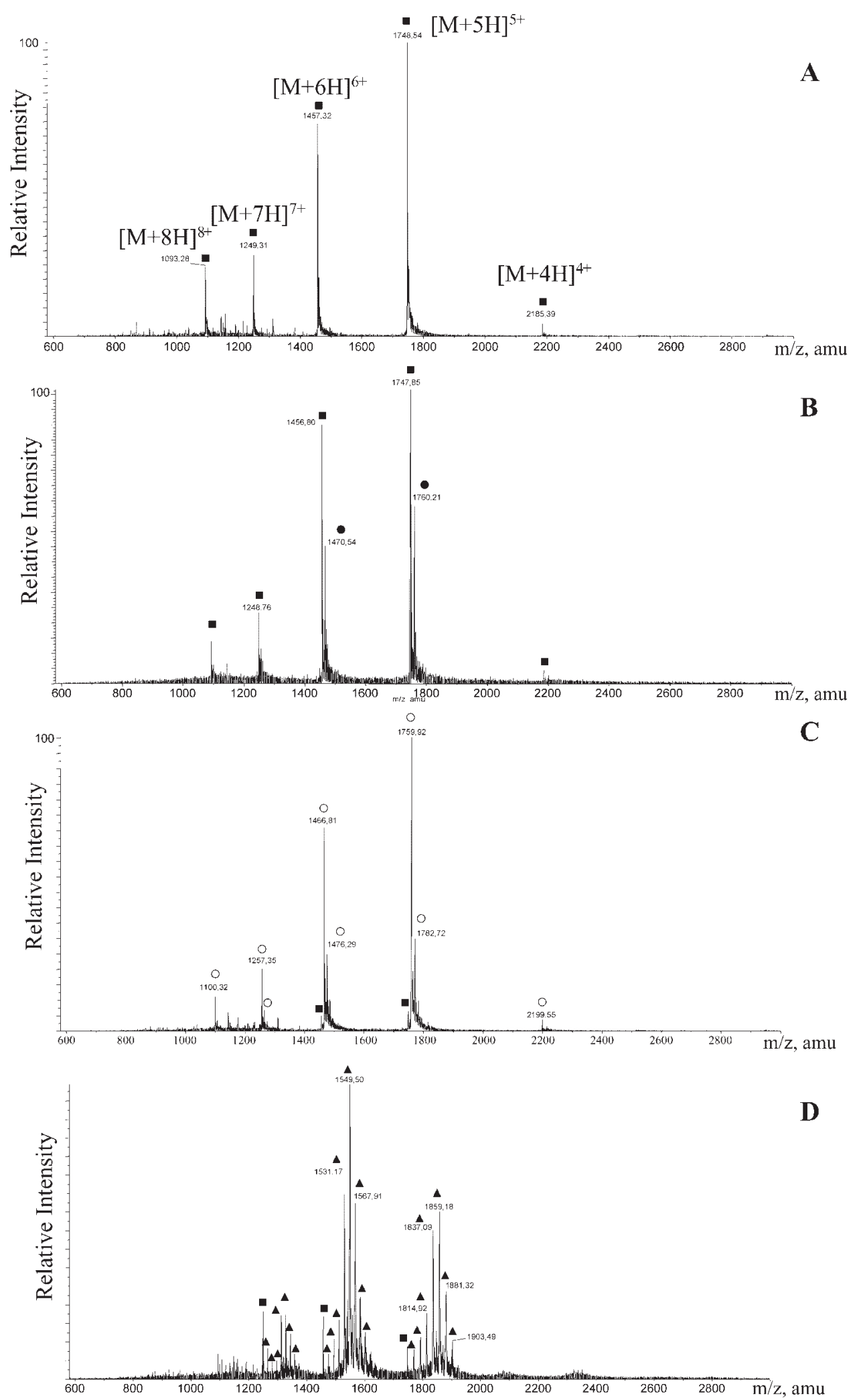

Figure 4. ESI mass spectra of the reduced CP12 protein without or with metal ions. (A) ESI mass spectrum of the free reduced CP12 protein. (B, C, D) ESI mass spectra of the reduced CP12 protein in the presence of $\mathrm{Cu}^{2+}(\mathrm{B}), \mathrm{Ni}^{2+}(\mathrm{C})$ and $\mathrm{Cd}^{2+}(\mathrm{D})$, at a molar ratio concentration of $1: 20$ with a fixed protein concentration of $5 \mu \mathrm{M}$. Labels $\mathbf{\square}$ : free CP12red, $\mathrm{CP} 12 / \mathrm{Cu}^{2+}$ complex, $\boldsymbol{\Delta}: \mathrm{CP} 12 / \mathrm{Cd}^{2+}$ complexes, $\mathrm{O}: \mathrm{CP} 12 / \mathrm{Ni}^{2+}$ complex.

free newly re-oxidized protein could correspond to a modified structure of CP12. Study of the $\mathrm{Ni}^{2+}$ cation binding to CP12red gave results very similar to those for CP12ox, with the $\mathrm{CP} 12 \mathrm{red} / \mathrm{Ni}^{2+}$ complex representing the major form Copyright (C) 2005 John Wiley \& Sons, Ltd. of the species and a low abundance of free CP12red (Fig. 4(C)). This indicates that $\mathrm{CP} 12$ red binds $\mathrm{Ni}^{2+}$ in the same manner as CP12ox, and that thiols are not involved in $\mathrm{Ni}^{2+}$ complexation.

D 


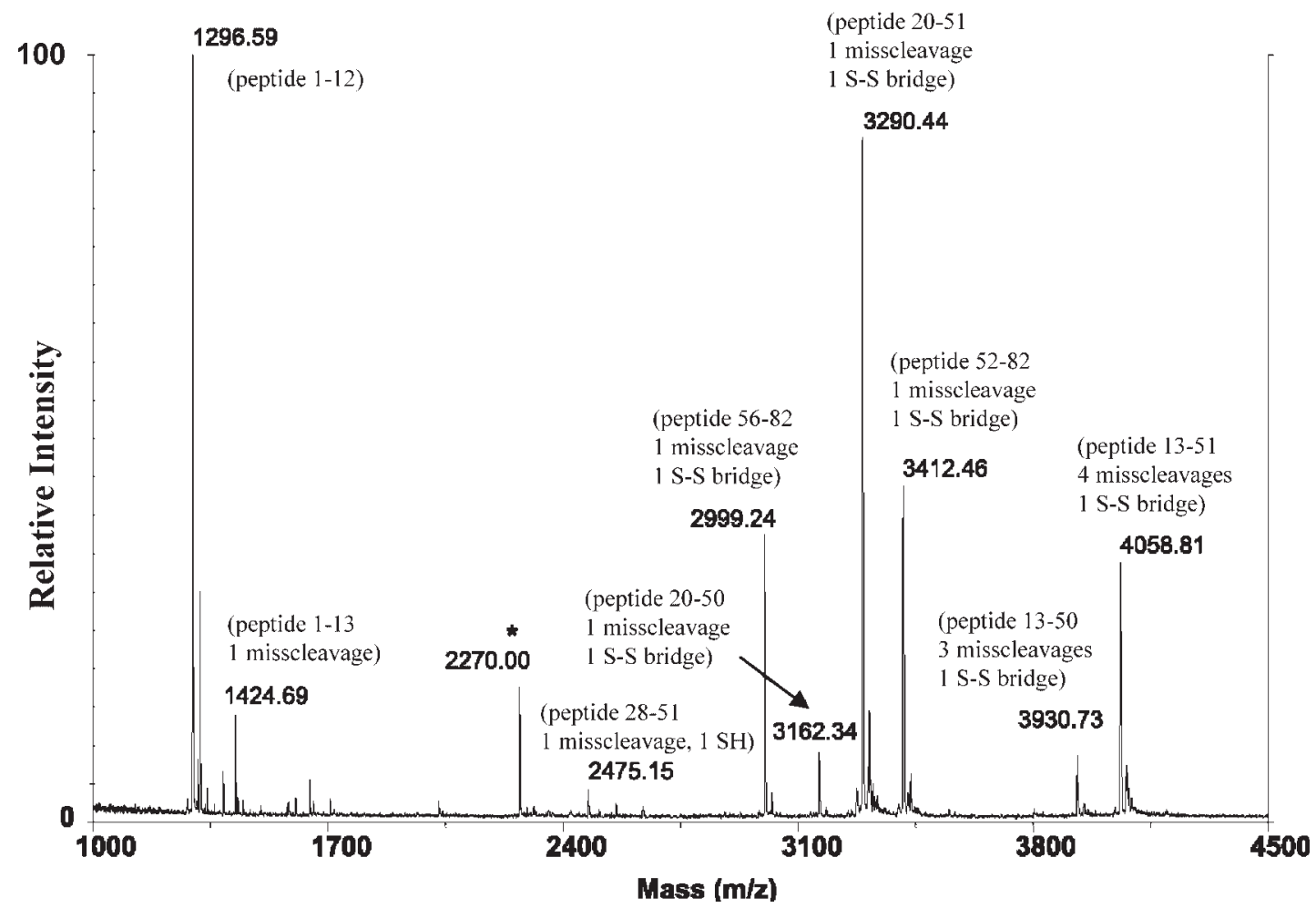

Figure 5. MALDI mass spectrum of the EndolysC peptides of $\mathrm{CP} 12^{*}$ ox protein obtained after addition of copper, showing the correct disulfide bond rearrangement upon copper binding. The stars correspond to unidentified peptides (e.g. non-specific cleavages).

\section{DISCUSSION}

Contrary to our expectations, our results unambiguously showed that $\mathrm{CP} 12$ does not bind $\mathrm{Zn}^{2+}$, ruling out our first hypothesis suggesting the presence of a zinc-binding domain. In contrast, we showed that, in its oxidized form, the small chloroplast protein $\mathrm{CP} 12$ specifically binds $\mathrm{Cu}^{2+}$ and $\mathrm{Ni}^{2+}$ with a low affinity (dissociation constants of $26 \pm 1$ and $11 \pm 1 \mu \mathrm{M}$, respectively). In particular, the $\mathrm{K}_{\mathrm{d}}$ value for $\mathrm{Cu}^{2+}$ is within the range of those obtained with the prion protein $\left(\mathrm{K}_{\mathrm{d}} \text { of about } 14 \mu \mathrm{M}\right)^{34}$ or copper chaperone proteins. $^{5,35}$

We then studied the behavior of the reduced CP12 to test whether the metal-ion-binding properties of the reduced form could be altered because of the presence of four free cysteine residues, or because of the structural disorganization that occurs upon reduction of $\mathrm{CP} 12$. We showed that the nickel ion binds to CP12red, with the same stoichiometry and peak-ratio intensity for both the CP12red $/ \mathrm{Ni}^{2+}$ and CP12ox forms. In contrast, $\mathrm{Cu}^{2+}$ binding exhibits a striking difference. Under non-denaturing conditions, when $\mathrm{Cu}^{2+}$ is added to the $\mathrm{CP} 12$ red solution, restoration of the disulfide bonds between the C23-C31 and C66-C75 cysteine residues was observed, leading to a newly oxidized CP12 (denoted $\mathrm{CP} 12^{*}$ ox) which has two disulfide bonds involving the same pair of cysteine residues as the original CP12ox (Fig. 5). This newly formed oxidized CP12 (CP12*ox) is then able to bind another $\mathrm{Cu}^{2+}$ cation. A similar disulfide bond formation catalyzed by $\mathrm{Cu}^{2+}$ and followed by the binding of the same metal was reported by McEwan et al. ${ }^{36}$ They suggest that $\mathrm{Cu}^{2+}$ may catalyze the formation of two disulfide bonds on the Sco protein, a protein required for copper delivery to cytochrome c oxidase. Moreover, this finding is also supported by the results obtained by Jensen et al., ${ }^{37}$ who showed that $\mathrm{Cu}^{2+}$, but not $\mathrm{Cu}^{+}$, is responsible for cysteine residue oxidation.

Surprisingly, the main species observed after re-oxidation of the cysteine residues by addition of a large excess of $\mathrm{Cu}^{2+}$ (protein/metal-ion ratio of 1:20) is the free CP12*ox. In the presence of such a high amount of $\mathrm{Cu}^{2+}$ in solution one would expect the main species to be the $\mathrm{CP} 12 * \mathrm{ox} / \mathrm{Cu}^{2+}$ complex, as was the case for the originalCP12ox. Even if part of the $\mathrm{Cu}^{2+}$ is used for disulfide rearrangement, the remaining $\mathrm{Cu}^{2+}$ in solution should suffice to promote the formation of the $\mathrm{CP} 12^{*} \mathrm{ox} / \mathrm{Cu}^{2+}$ complex. This discrepancy could be explained by either (i) the production of a $\mathrm{CP} 12^{*}$ ox protein with a structure less capable of binding $\mathrm{Cu}^{2+}$, or (ii) the requirement of a non-stoichoimetric higher amount of $\mathrm{Cu}^{2+}$ to re-oxidize the disulfide bonds. Regarding the first possibility (i), a different conformation for $\mathrm{CP} 12 *$ ox cannot be deduced from the CSD, as it was similar for both CP12*ox (Fig. 4(B)) and CP12ox (Fig. 1(A)). Protein structure recovery upon binding of a metal ion has already been observed for other proteins, such as prion proteins upon $\mathrm{Cu}^{2+}$ binding, ${ }^{38}$ human $\alpha$-prothymosin in the presence of $\mathrm{Zn}^{2+},{ }^{21}$ or calbindin in the presence of $\mathrm{Ca}^{2+}, 39,40$ but such structural modifications are only subtle and cannot be observed by CSD changes in ESI mass spectra. Consequently, at this point, one cannot rule out the possibility that disulfide bond formation of $\mathrm{CP} 12 \mathrm{by} \mathrm{Cu}^{2+}$ could result in a CP12*ox having a slightly different conformation compared with the original $\mathrm{CP} 12 \mathrm{ox}$. As proposition (ii), the disulfide bond re-oxidation of $\mathrm{CP} 12$ red could require a higher amount 

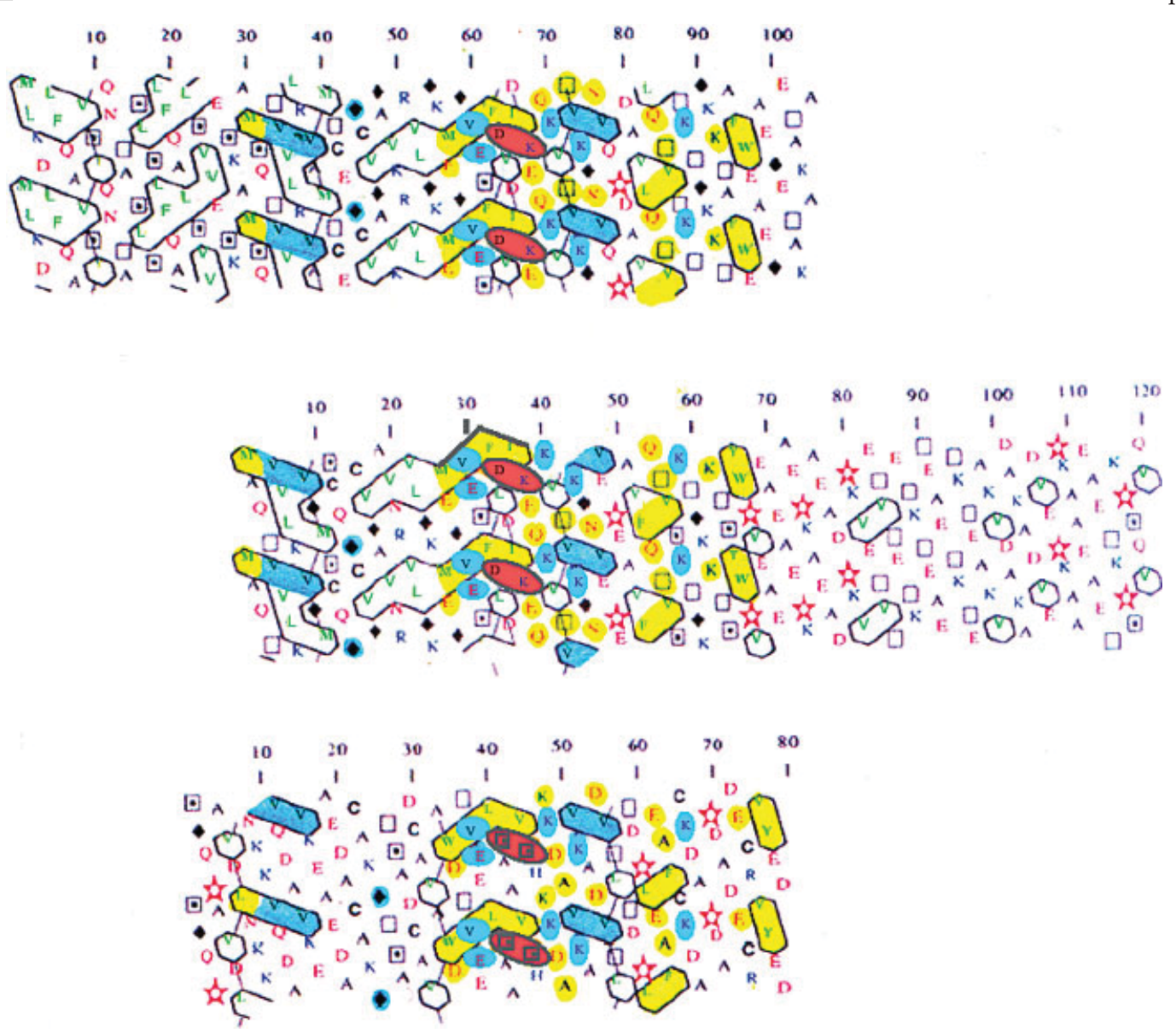

Figure 6. HCA plot comparison of copper chaperones from Arabidopsis thaliana and CP12 from Chlamydomonas reinhardtii. Two copper chaperones from Arabidopsis (accession number: AAK 64002, AAC33510) and CP12 from Chlamydomonas are represented. Special symbols, a diamond, a star, a square and a square with a point, are used for proline, glycine, threonine and serine. Hydrophobic residues are boxed and formed clusters that mainly correspond to the internal sides of regular secondary structures. Sequence homologies are associated with blue (identical residues), yellow (conserved substitutions) and red color (semi-conservative substitutions).

of $\mathrm{Cu}^{2+}$ if the catalysis occurred in a non-stoichiometric manner. This last proposition is supported by the results of Jensen et al., who showed that thiol re-oxidation is induced by $\mathrm{Cu}^{2+}$ in a non-stoichiometric manner. ${ }^{37}$

At this point, the mechanism responsible for the reformation of the two disulfide bonds remains unclear. The disulfide bond rearrangement could occur via the binding of one $\mathrm{Cu}^{2+}$ tetra-coordinated to the four thiols of the CP12red, catalyzing their re-oxidation, or via the binding of one $\mathrm{Cu}^{2+}$ to two cysteine residues, catalyzing the formation of a first disulfide bond, with the second pair of cysteine residues being re-oxidized afterwards. The oxidation kinetics experiment that we performed does not enable us to rule out one of the two hypotheses. It is possible that, in the case of a sequential mechanism, the formation of the first disulfide bond could be too fast to be observed. This mechanism could be supported by the existence of a more reactive pair of cysteine residues, favored by the presence of a thiolate on the CP12red. It is also noteworthy that the reduced CP12, when left in the presence of air for a few hours, showed the formation of one disulfide bond with the two remaining cysteine residues still reduced. Consequently, a sequential reoxidation to form disulfide bonds is the most likely mechanism for CP12.

Copyright (C) 2005 John Wiley \& Sons, Ltd.
All the present MS experiments clearly showed that only the natural oxidized form of $\mathrm{CP} 12$ and the form that originates from the reduced $\mathrm{CP} 12$ upon $\mathrm{Cu}^{2+}$ binding are able to bind $\mathrm{Cu}^{2+}$, and that cysteine residues are not involved in the metal-ion binding. However, disulfide bridges are essential for CP12 re-folding prior to metal-ion binding. Consequently, copper binding may involve carboxylic groups of glutamic or aspartic residues or the imidazole of histidine residues. ${ }^{21}$ Since sequence analysis showed that histidine 47 was strongly conserved among different CP12 sequences from many organisms, a CP12 H47L mutant was tested for its capacity to bind $\mathrm{Cu}^{2+}$. No effect was observed, thus rejecting the involvement of this residue in metal-ion binding.

The finding that CP12 is able to bind a metal ion is another new characteristic of this protein that may prove to be important in the redox regulation of the assembly process of the PRK/GAPDH/CP12 complex. This result is similar to that of $\mathrm{Hsp} 33^{41,42}$ and Toc $64,^{43}$ two proteins that are regulated by reversible disulfide bond formation induced by $\mathrm{Cu}^{2+}$. Plants are faced with the challenge to maintain metal homeostasis, and copper chaperones like those in mammals or yeast have been described. Recent work on the Arabidopsis genome suggests that these chaperones have acquired 
additional functions and played different roles in copper homeostasis. ${ }^{44}$ All these points led us to perform hydrophobic cluster analysis (HCA) to compare CP12 and copper chaperones. Indeed, the sensitivity of HCA has often been successfully used to identify new domains ${ }^{45,46}$ and/or to link orphan sequences to particular structural and functional families. ${ }^{47-49}$ In the case of CP12, the HCA result shown in Fig. 6 demonstrated a high structural similarity with copper chaperones from $A$. thaliana ${ }^{43,50,51}$ Knowing that these copper chaperones have been shown to be involved in copper homeostasis and to facilitate copper transfer to specific partners, we can hypothesize that CP12 is a metallochaperone that can play a role in the PRK/GAPDH activity regulation during the light and dark activation of the Calvin-Benson cycle.

\section{CONCLUSIONS AND FUTURE DIRECTIONS}

The experiments reported here show that oxidized CP12 specifically binds $\mathrm{Cu}^{2+}$ and $\mathrm{Ni}^{2+}$ with $\mathrm{K}_{\mathrm{d}}$ values calculated from the MS data of $26 \pm 1 \mu \mathrm{M}$ and $11 \pm 1 \mu \mathrm{M}$, respectively. Similar results were obtained with the reduced $\mathrm{CP} 12$. Interestingly, our results showed that $\mathrm{Cu}^{2+}$ catalyzes the re-formation of the disulfide bonds of the reduced $\mathrm{CP} 12$, leading to the recovery of the fully oxidized CP12 that is then able to bind a $\mathrm{Cu}^{2+}$ ion. Finally, the high similarity between CP12 and copper chaperones from Arabidopsis thaliana, as judged by HCA, is additional evidence for the relevance of metal binding in vivo.

To go further in our understanding of CP12 copper regulation, the confirmation of the binding constant values for copper and nickel could be assessed by alternative solution-based techniques such as differential scanning calorimetry. In addition, the design of limited proteolysis experiments or electron capture dissociation experiments, associated with site-directed mutageneses, would also be very helpful to identify the site of metal-ion binding.

\section{Acknowledgements}

Arnaud Delobel is indebted to the Institut de Chimie des Substances Naturelles (CNRS) for a PhD research fellowship.

\section{REFERENCES}

1. Puig O, Caspary F, Rigaut G, Rutz B, Bouveret E, BragadoNilsson E, Wilm M, Seraphin B. Methods 2001; 24: 218.

2. Landgraf C, Panni S, Montecchi-Palazzi L, Castagnoli L, Schneider-Mergener J, Volkmer-Enger R, Cesareni G. PLoS Biol. 2004; 2: 94.

3. Gavin AC, Bosche M, Krause R, Grandi P, Marzioch M, Bauer A, Schultz J, Rick JM, Michon AM, Cruciat CM, Remor M, Hofert C, Schelder M, Brajenovic M, Ruffner H, Merino A, Klein K, Hudak M, Dickson D, Rudi T, Gnau V, Bauch A, Bastuck S, Huhse B, Leutwein C, Heurtier MA, Copley RR, Edelmann A, Querfurth E, Rybin V, Drewes G, Raida M, Bouwmeester T, Bork P, Seraphin B, Kuster B, Neubauer G, Superti-Furga G. Nature 2002; 415: 141.

4. Heck AJ, Van Den Heuvel RH. Mass Spectrom. Rev. 2004; 23: 368.

5. Wortmann A, Rossi F, Lelais G, Zenobi R. J. Mass Spectrom. 2005; 40: 777

6. Gabelica V, Galic N, Rosu F, Houssier C, De Pauw E. J. Mass Spectrom. 2003; 38: 491.
7. Ayed A, Krutchinsky AN, Ens W, Standing KG, Duckworth HW. Rapid Commun. Mass Spectrom. 1998; 12: 339.

8. Urvoas A, Amekraz B, Moulin C, Le Clainche L, Stocklin R, Moutiez M. Rapid Commun. Mass Spectrom. 2003; 17: 1889.

9. Whittal RM, Ball HL, Cohen FE, Burlingame AL, Prusiner SB, Baldwin MA. Protein Sci. 2000; 9: 332.

10. Tjernberg A, Carno S, Oliv F, Benkestock K, Edlund PO, Griffiths WJ, Hallen D. Anal. Chem. 2004; 76: 4325.

11. Clasper S, Easterby JS, Powls R. Eur. J. Biochem. 1991; 202: 1239.

12. Scheibe R, Wedel N, Vetter S, Emmerlich V, Sauermann SM. Eur. J. Biochem. 2002; 269: 5617.

13. Avilan L, Gontero B, Lebreton S, Ricard J. Eur. J. Biochem. 1997; 250: 296.

14. Wedel N, Soll J. Proc. Natl. Acad. Sci. USA 1998; 95: 9699.

15. Nicholson S, Easterby JS, Powls R. Eur. J. Biochem. 1987; 162: 423.

16. O'Brien MJ, Easterby JS, Powls R. Biochim. Biophys. Acta 1976; 449: 209.

17. Wedel N, Soll J, Paap BK. Proc. Natl. Acad. Sci. USA 1997; 94: 10479.

18. Sparla F, Pupillo P, Trost P. J. Biol. Chem. 2002; 277: 44946

19. Graciet E, Gans P, Wedel N, Lebreton S, Camadro JM, Gontero B. Biochemistry 2003; 42: 8163.

20. Uversky VN, Gillespie JR, Fink AL. Proteins 2000; 41: 415

21. Uversky VN, Gillespie JR, Millett IS, Khodyakova AV, Vasilenko RN, Vasiliev AM, Rodionov IL, Kozlovskaya GD, Dolgikh DA, Fink AL, Doniach S, Permyakov EA, Abramov VM. Biochem. Biophys. Res. Commun. 2000; 267: 663.

22. Uversky VN. Protein Sci. 2002; 11: 739.

23. Uversky VN. Eur. J. Biochem. 2002; 269: 2

24. Uversky VN. Cell. Mol. Life Sci. 2003; 60: 1852.

25. Uversky VN, Fink AL. Biochim. Biophys. Acta 2004; 1698: 131.

26. Bradford MM. Anal. Biochem. 1976; 72: 248.

27. Arnesano F, Banci L, Bertini I, Mangani S, Thompsett AR. Proc. Natl. Acad. Sci. USA 2003; 100: 3814

28. Available: http://www.OriginLab.com.

29. Gray WR. Protein Sci. 1993; 2: 1732.

30. Gaboriaud C, Bissery V, Benchetrit T, Mornon JP. FEBS Lett. 1987; 224: 149.

31. Callebaut I, Labesse G, Durand P, Poupon A, Canard L, Chomilier J, Henrissat B, Mornon JP. Cell. Mol. Life Sci. 1997; 53: 621 .

32. Woodcock S, Mornon JP, Henrissat B. Protein Eng. 1992; 5: 629 .

33. Lippard SJ, Berg JM. Principles of coordination chemistry related to bioinorganic research. In Principles of Bioinorganic Chemistry, Kelly A (ed). University Science Books: Mill Valley, 1994; 21.

34. Stöckel J, Safar J, Wallace FE, Prusiner SB. Biochemistry 1998; 37: 7185 .

35. Multhaup G, Strausak D, Bissig KD, Solioz M. Biochem. Biophys. Res. Commun. 2001; 288: 172.

36. McEwan AG, Lewin A, Davy SL, Boetzel R, Leech A Walker D, Wood T, Moore GR. FEBS Lett. 2002; 518: 10.

37. Jensen PY, Bonander N, Horn N, Tumer Z, Farver O. Eur. J. Biochem. 1999; 264: 890.

38. Stockel J, Safar J, Wallace AC, Cohen FE, Prusiner SB Biochemistry 1998; 37: 7185.

39. Berggard T, Silow M, Thulin E, Linse S. Biochemistry 2000; 39: 6864.

40. Berggard T, Miron S, Onnerfjord P, Thulin E, Akerfeldt KS, Enghild JJ, Akke M, Linse S. J. Biol. Chem. 2002; 277: 16662.

41. Jakob U, Muse W, Eser M, Bardwell JC. Cell 1999; 96: 341.

42. Jakob U, Eser M, Bardwell JC. J. Biol. Chem. 2000; 275: 38302.

43. Sohrt K, Soll J. J. Cell. Biol. 2000; 148: 1213.

44. Wintz H, Vulpe C. Biochem. Soc. Trans. 2002; 30: 732.

45. Callebaut I, Mornon JP. FEBS Lett. 1997; 400: 25.

46. Callebaut I, de Gunzburg J, Goud B, Mornon JP. Trends Biochem. Sci. 2001; 26: 79.

47. Callebaut I, Mornon JP. Cell. Mol. Life Sci. 1998; 54: 880.

48. Girault JA, Labesse G, Mornon JP, Callebaut I. Trends Biochem. Sci. 1999; 24: 54

49. Corneo B, Moshous D, Callebaut I, de Chasseval R, Fischer A, de Villartay JP. J. Biol. Chem. 2000; 275: 12672.

50. Mira H, Vilar M, Perez-Paya E, Penarrubia L. Biochem. J. 2001; 357: 545.

51. Himelblau E, Mira H, Lin SJ, Culotta VC, Penarrubia L, Amasino RM. Plant Physiol. 1998; 117: 1227. 